\title{
Inhibition of tumorigenesis and invasion of hepatocellular carcinoma by siRNA-mediated silencing of the livin gene
}

\author{
HUI LIU ${ }^{1 *}$, SHAOCHUANG WANG ${ }^{2 *}$, HANGYONG SUN ${ }^{1}$, \\ ZEYA PAN $^{1}$, WEIPING ZHOU ${ }^{1}$ and MENGCHAO WU ${ }^{1}$ \\ ${ }^{1}$ The 3rd Department of Hepatic Surgery, Eastern Hepatobiliary Surgery Hospital, Second Military Medical University, \\ Shanghai 200438; ${ }^{2}$ Department of Hepatobiliary Pancreatic Surgery, The Huai'an First People's \\ Hospital Affiliated to Nanjin Medical University, Huai'an, Jiangsu 223300, P.R. China
}

Received May 31, 2010; Accepted August 15, 2010

DOI: $10.3892 / \mathrm{mmr} .2010 .355$

\begin{abstract}
Livin, a member of the inhibitor of apoptosis protein family, is overexpressed in a variety of solid tumors and cancer cell lines. Livin overexpression has been reported in hepatocellular carcinoma (HCC), suggesting the biological significance of livin in HCC progression. However, the mechanisms of livin and the consequence of its down-regulation in HCC have not been fully elucidated. A small interfering RNA (siRNA) eukaryotic expression vector specific to livin was constructed by gene recombination, and the nucleic acid was sequenced. It was then transfected into the human HCC cell line SMMC-7721. RT-PCR and Western blotting were used to validate the gene-silencing efficiency of livin in SMMC7721 cells. Stable clones were obtained by G418 screening. Using multiple cellular and molecular approaches, such as an apoptosis assay, MTT assay, flow cytometry, Western blotting and a migration assay, the effects of livin inhibition on cell growth, migration and the induction of apoptosis in SMMC-7721 cells were observed. The siRNA eukaryotic expression vector specific to livin was constructed by gene recombination, and efficiently decreased the mRNA and protein expression of livin. The targeted inhibition of livin strongly sensitized SMMC-7721 cells to pro-apoptotic stimuli, and was associated with caspase-3 activation. In addition, the MMT assay indicated that the silencing of livin inhibited the cell growth of SMMC-7721 cells by specifically inhibiting cell mitosis. The results also showed that the silencing of livin strongly reduced the invasive capacity of SMMC-7721 cells. The findings suggest that livin expression not only provides HCC cells with increased resistance to apoptotic stimuli, but
\end{abstract}

Correspondence to: Professor Weiping Zhou, The 3rd Department of Hepatic Surgery, Eastern Hepatobiliary Surgery Hospital, Second Military Medical University, Shanghai 200438, P.R. China

E-mail: weiping.zhou@hotmail.com

${ }^{*}$ Contributed equally

Key words: hepatocellular carcinoma, livin, RNA interference, proliferation, invasion also contributes significantly to the proliferation and invasive capacity of HCC cells. Inhibition of livin may be a potential targeted approach for the treatment of HCC.

\section{Introduction}

Hepatocellular carcinoma (HCC) is the fifth most common cancer worldwide by annual incidence and the third leading cause of cancer mortality (1). Currently, surgery remains the first choice for HCC clinical therapy. However, the prognosis for $\mathrm{HCC}$ is poor, and the 5-year survival rate worldwide is less than $5 \%$, mainly because of a high potential for tumor growth, vascular invasion, metastasis and recurrence even after surgical resection (2). Hence, novel treatment methods and agents for $\mathrm{HCC}$ are required.

Livin (officially named BIRC7) is a member of the inhibitor of apoptosis protein (IAP) family, and is a key regulator of apoptosis, cytokinesis and signal transduction (3-5). Livin has a baculovirus IAP repeat (BIR) protein domain and a RING domain that allow it to act as a E3 ubiquitin ligase. The E3 ubiquitin ligase activity of livin protein is capable of promoting ubiquitination and the proteasomal degradation of caspases, TRAF2 and several other partners (6).

Livin has been found to be overexpressed in tumors including melanoma, breast, cervical, colon and prostate cancer, as well in leukemia, lymphoma and hepatoma cell lines. It has been proposed that endogenous livin has a minor direct effect on caspase activity, whereas its anti-apoptotic effect may be ascribed to its antagonizing activity on XIAPSmac/DIABLO interaction. Moreover, studies have shown that overexpression of livin $\alpha$ isoform is correlated with a high risk of relapse in bladder cancer (7). A recent study documented that the livin gene is overexpressed in HCC, although its expression level was not significantly associated with patient survival (8). Taken together, these reports suggest that livin may play a role in the development and progression of cancer, including $\mathrm{HCC}$.

In the present study, to explore the effect of livin expression in $\mathrm{HCC}$ and to validate its potential as a novel therapeutic target, endogenous livin expression was efficiently and specifically inhibited in the HCC SMMC-7721 cell line by small interfering RNA (siRNA). The data indicated that the 
targeted silencing of livin gene expression efficiently inhibited HCC cell growth and migration. Thus, the targeted inhibition of livin may represent a novel strategy for improving the therapeutic response of $\mathrm{HCC}$.

\section{Materials and methods}

Construction of pSilencer 2.1-U6 neo-Livin siRNA plasmids. To prepare the silencer RNA construct for livin, human livin mRNA sequences (accession nos. NM_022161 and NM_139317) were analyzed using the web-based siRNA target finder and design tool provided on the Ambion website (Ambion, Inc., Austin, TX, USA). The DNA sequence of the livin RNAi (sense, 5'-GAGAGGUCCAGUCUGAAAGdTdT-3'; antisense, 5'-CUUUCAGACUGGACCUCUCdTdT-3') was synthesized and cloned into the pSilencer 2.1-U6 neo (Ambion) according to the manufacturer's instructions, and consisted of a BamHI DNA restriction site, sense strand, 9-nucleotide loop, antisense strand, RNA polymerase III terminator and HindIII DNA restriction site 5' to 3 '. The plasmid carrying the livin siRNA sequence was named pU-siLivin. Human specific negative control siRNA (pU-siNC) were also designed, with the following sequences: sense, 5'-UUCUCCGAACGUGUACGUdTdT-3'; antisense, 5'-ACGUGACACGUUCGGAGAAdTdT-3'.

Cell line and establishment of stable transfectants expressing $p U$-siLivin and $p U$-siNC. The human HCC SMMC-7721 cell line was provided by the Eastern Hepatobiliary Surgery Hospital, Second Military Medical University (China). The cells were grown in RPMI1640 medium (Gibco, USA) containing $1 \%$ penicillin/streptomycin and $10 \%$ fetal bovine serum (Invitrogen, Carlsbad, CA, USA), and were maintained at $37^{\circ} \mathrm{C}$ in a humidified incubator with a $5 \% \mathrm{CO}_{2}$ atmosphere. The day before transfection, the cells were plated in 6 -well plates at a density of $4 \times 10^{5}$ cells/well. The cells were transfected with $4 \mathrm{mg} /$ well of pU-siLivin or pU-siNC using Lipofectamine $^{\text {TI }} 2000$ following the manufacturer's instructions (Invitrogen), then cultured in medium supplemented with Geneticin (G418) at $400 \mu \mathrm{g} / \mathrm{ml}$ for 4 weeks. Stably transfected clones were selected and maintained in medium containing $100 \mu \mathrm{g} / \mathrm{ml} \mathrm{G} 418$ for additional study.

RNA isolation and semi-quantitative reverse transcription polymerase chain reaction (RT-PCR). Total RNA was purified from SMMC-7721 cells using TRIzol reagent (Life Technologies, Carlsbad, CA, USA). First-strand cDNA was synthesized using $2.5 \mu \mathrm{g}$ RNA and AMV retroviridase (Promega, Madison, WI, USA). To determine the levels of the genes, primers for the PCR of livin $\alpha$, livin $\beta$, and $\beta$-actin were designed as follows: livin $\alpha$ and livin $\beta$, tccacagtgtgcaggagact and acggcacaaagacgatggac; $\beta$-actin, agcgcaagtactccgtgtg and aagcaatgctatcacctccc. The sizes of the amplified products were $312 \mathrm{bp}$ for livin $\alpha, 258 \mathrm{bp}$ for livin $\beta$, and $501 \mathrm{bp}$ for $\beta$-actin. A 2X PCR Master Mix (Fermentas, Burlington, Ontario, Canada) was employed, and $\beta$-actin was co-amplified as an endogenous control to standardize the amount of sample RNA added to the reaction. PCR conditions were as follows: $95^{\circ} \mathrm{C}$ for $5 \mathrm{~min}$ to activate the hot-start DNA polymerase, followed by 35 cycles at $95^{\circ} \mathrm{C}$ for $30 \mathrm{sec}, 58^{\circ} \mathrm{C}$ for $30 \mathrm{sec}$ and $72^{\circ} \mathrm{C}$ for $30 \mathrm{sec}$. Amplified PCR products were electrophoresed with DNA markers on $8 \%$ (w/v) agarose gels containing ethidium bromide. Bands were visualized under UV light and each gel image was captured using a digital camera. Imagetool 2.0 software was used for semi-quantitative analysis of the electrophoresis results.

Protein isolation and Western blotting. Cells at $80 \%$ culture confluence were harvested for Western blotting. The harvested cells were lysed and their protein concentrations were determined using a BCA protein assay (Pierce, Rockford, IL, USA). The cell lysates (50 $\mu \mathrm{g}$ of protein per lane) were separated by $10 \%$ sodium dodecyl sulfate-polyacrylamide gel electrophoresis (SDS-PAGE) and transferred onto nitrocellulose membranes (Hyclone, Logan, UT, USA). The membranes were blocked with $5 \%(\mathrm{v} / \mathrm{v})$ skim milk and probed with primary antibody at $4^{\circ} \mathrm{C}$ overnight. Following washing, the membranes were incubated with HRP-conjugated secondary antibody at room temperature for $1 \mathrm{~h}$. Primary antibodies were specific for Livin, caspase-3, $-7,-8$ and -9 and $\beta$-actin (Santa Cruz Biotechnology, CA, USA). The bound antibodies were visualized using an ECL system (Amersham Pharmacia Biotech, Piscataway, NJ, USA).

Treatment with pro-apoptotic agents and TUNEL analysis. For treatment with pro-apoptotic agents, the cells were grown on coverslips and exposed for $48 \mathrm{~h}$ to a single dose of $50 \mathrm{~J} / \mathrm{m}^{2}$ UV-irradiation and harvested $20 \mathrm{~h}$ later. TdT-mediated dUTP nick end labeling (TUNEL) analysis for the detection of apoptosis was performed using an in situ cell death detection kit (Roche Molecular Biochemicals, Mannheim, Germany). Nuclei were stained with 4',6-diamidino-2-phenylindole (DAPI) (Roche Molecular Biochemicals). Apoptotic strand breaks and total DNA were visualized using fluorescence microscopy.

MTT assay. Exponentially growing cells were plated onto 96-well plates at a density of $1 \times 10^{5}$ cells/well for 7 days. MTT stock solution $(100 \mu \mathrm{l}, 1 \mathrm{mg} / \mathrm{ml})$ was added to each well every day, and the cells were further incubated at $37^{\circ} \mathrm{C}$ for $4 \mathrm{~h}$. The supernatant was replaced with isopropyl alcohol to dissolve formazan production. Absorbance was measured at a wavelength of $595 \mathrm{~nm}$ with a micro-ELISA reader.

Flow cytometry analysis for cell cycles. The cells were collected and fixed with ice-cold $70 \%$ ethanol in PBS, then stored at $-4^{\circ} \mathrm{C}$ until use. After resuspension, the cells were incubated with $100 \mathrm{ml}$ of RNase I $(1 \mathrm{mg} / \mathrm{ml})$ and $100 \mathrm{ml}$ of propidium iodide $(400 \mathrm{mg} / \mathrm{ml})$ at $37^{\circ} \mathrm{C}$, and analyzed using flow cytometry (BD Biosciences, San Jose, CA, USA).

Cell invasion. Invasion was measured using a $24-w e l l, ~ 8-\mu \mathrm{m}$ pore size matrigel-coated Transwell chamber assay (Corning Inc., Corning, NY, USA) according to the manufacturer's recommendations. Briefly, filters were pre-coated on the upper side with Matrigel (20 $\mu \mathrm{g}$ per well; BD Biosciences). The cells $\left(1 \times 10^{5}\right)$ were seeded in serum-free RPMI 1640 in the upper compartment of the chambers for $16 \mathrm{~h}$ at $37^{\circ} \mathrm{C}$. The membranes were photographed using a bright field and images of five consecutive vertical fields of view were captured using a 10X objective lens. The number of cells in each field of view was counted manually. For all conditions, a minimum of three replicate chambers was analyzed. 
A

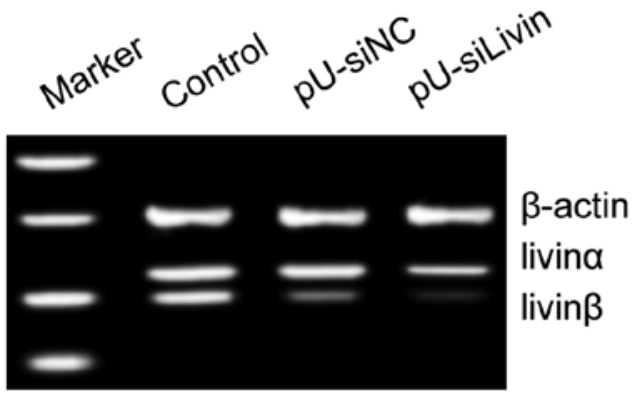

C

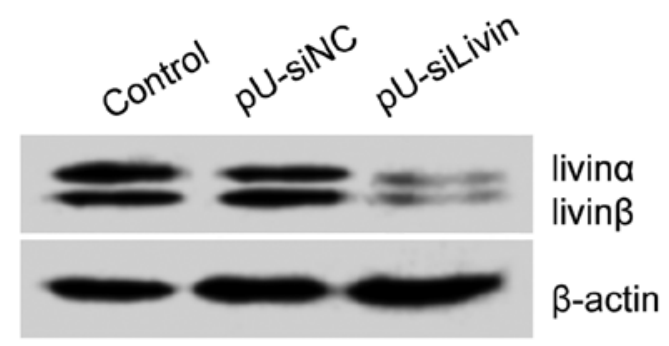

B

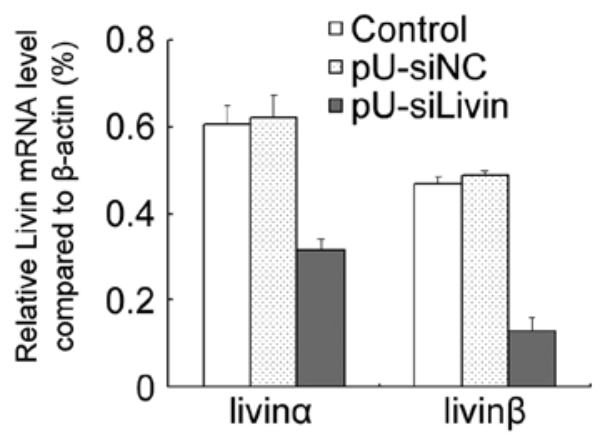

$\mathbf{D}$

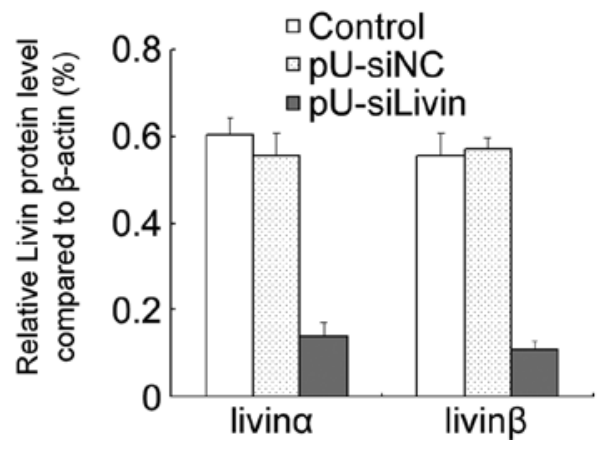

Figure 1. siRNA-mediated inhibition of livin expression in HCC cells. (A) RT-PCR analysis of Livin mRNA expression in SMMC-7721 cells. (B) Histograms showing the relative expression levels of livin mRNA. Each bar represents the mean \pm SD. (C) Western blotting of livin protein expression in SMMC-7721 cells. (D) Histograms showing the relative expression levels of livin protein. Each bar represents the mean \pm SD. The experiments were repeated three times, with similar results.

Statistical analysis. Data are presented as means \pm SE. Differences in the variables between groups were analyzed using Student's t-test or a one-way ANOVA test. Differences were considered significant at $\mathrm{P}<0.05$.

\section{Results}

Silencing of livin gene expression in HCC cells by RNAi. To investigate the effect of livin expression in HCC cells, siRNA technology was used to silence the livin gene. In order to confirm the RNAi-induced down-regulation of livin mRNA and protein levels in SMMC-7721 cells, RT-PCR and Western blotting were performed. After transfection and G418 selection, endogenous livin mRNA and protein expression levels were significantly reduced by pU-siLivin in SMMC-7721 cells as compared to the control transfections (Fig. 1). As shown in Fig. $1 \mathrm{~B}$ and $\mathrm{D}$, the mRNA levels of livin $\alpha$ and livin $\beta$ in the pU-siLivin transfectants were reduced by $>50$ and $73 \%$, respectively, and the protein levels of livin $\alpha$ and livin $\beta$ were reduced by 76 and $80 \%$, respectively. The suppression of livin expression was not observed in the pU-siNC transfectants. Therefore, the pU-siLivin transfectants were chosen for subsequent experiments. In contrast to livin, the amounts of cellular $\beta$-actin mRNA and protein were not affected by either pU-siLivin or pU-siNC.

Sensitization of HCC cells to pro-apoptotic stimuli. Whether pU-siLivin can sensitize livin-positive SMMC-7721 cells to pro-apoptotic stimuli was next investigated. Livin gene expression was selectively silenced by RNAi and cells were treated with the pro-apoptotic agent, UV-irradiation. Apoptotic cells were identified by their typical nuclear morphology (DAPI staining) as well as by positive TUNEL assay results. As shown in Fig. 2, siRNA-mediated silencing of livin efficiently sensitized SMMC-7721 cells towards UV-irradiation and led to a strong increase in the number of apoptotic cells. The number of apoptotic cells induced by UV-irradiation increased to about 8-fold in the pU-siLivin transfectants compared to the control cells $(\mathrm{P}<0.05$; Fig. 2B). As shown in Fig. 2C, pU-siLivin clearly increased the protein level of the active form of caspase-3, but not of caspase- $7,-8$ or -9 , following treatment of SMMC-7721 cells with UV-irradiation as compared to the control cells. UV-irradiation promoted cleavage of the caspase substrate poly (ADP-ribose) polymerase (PARP), and increased the faster migrating PARP cleavage product by inhibiting the expression of livin.

Inhibitory effects of livin on HCC cell growth. In order to observe the effects of livin on the growth of SMMC-7721 cells, MTT and flow cytometry assays were performed. As shown in Fig. 3A, down-regulation of livin expression by siRNA caused the cell growth inhibition of the SMMC-7721 cell line. The cell growth index of the pU-siLivin transfectants was significantly decreased by days 3 and 4 after plating compared to the two control groups $(\mathrm{P}<0.05)$. Flow cytometry assay showed that pU-siLivin induced SMMC-7721 cell arrest at the G1 phase of the cell cycle (Fig. 3B). The number of cells in the G1 phase increased from 40.1 to $70.72 \%$ after livin siRNA transfection, while the number of cells in the $\mathrm{S}$ phase decreased from 44.96 to $9.7 \%$. Thus, pU-siLivin specifically inhibited cell mitosis.

Effects of livin inhibition on HCC cell invasion. The number of cells that crossed the membrane of the Transwell migration chamber within $24 \mathrm{~h}$ were compared among three groups. We found that the down-regulation of livin decreased HCC cell migration. As shown in Fig. 4, livin siRNA-transfected cells 
A
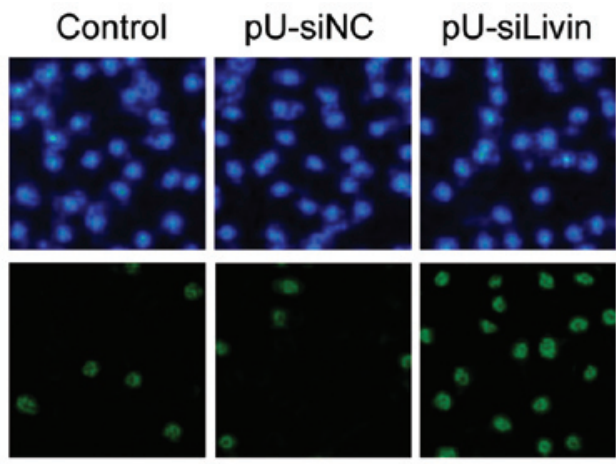

B

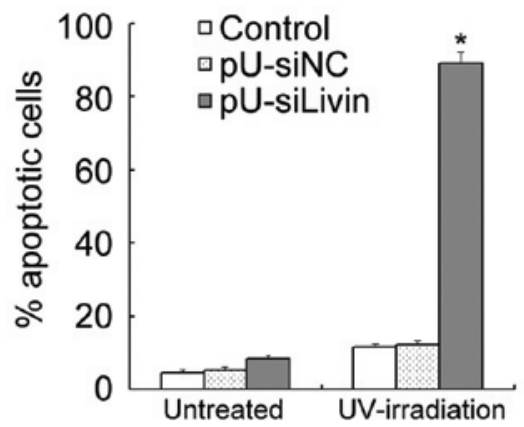

C
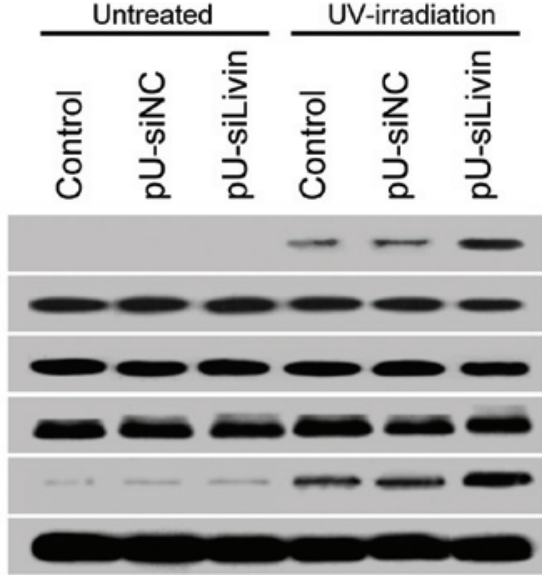

Caspase-3

Caspase-7

Caspase-8

Caspase-9

PARP

$\beta$-actin

Figure 2. Inhibition of livin sensitizes HCC cells to pro-apoptotic stimuli. Cells were subsequently exposed to UV-irradiation. (A) Detection of apoptotic cells after UV-irradiation. Nuclei were stained with DAPI, and cells undergoing apoptosis were visualized using the TUNEL assay. (B) Percentage of apoptotic cells. Each bar represents the mean \pm SD. ${ }^{~} \mathrm{P}<0.05$. (C) Western blotting of the protein expression of caspases and PARP in pUsiLivin, pU-siNC transfected HCC cells, or in control cells, either untreated or following exposure to UV-irradiation. The experiments were repeated three times, with similar results.

showed a lower level of penetration through the matrigelcoated membrane than the two controls $(\mathrm{P}<0.05)$, while differences between the other two groups were not significant. The number of the invaded SMMC-7721 cells was decreased about 9-fold compared to that of the control cells (Fig. 4B), suggesting a significant role of livin in HCC cell migration and invasion.

\section{Discussion}

Livin is utilized by cancer cells to antagonize cell apoptosis, and is reported to be overexpressed in HCC cell lines (8). The expression of livin is often associated with poor prognosis
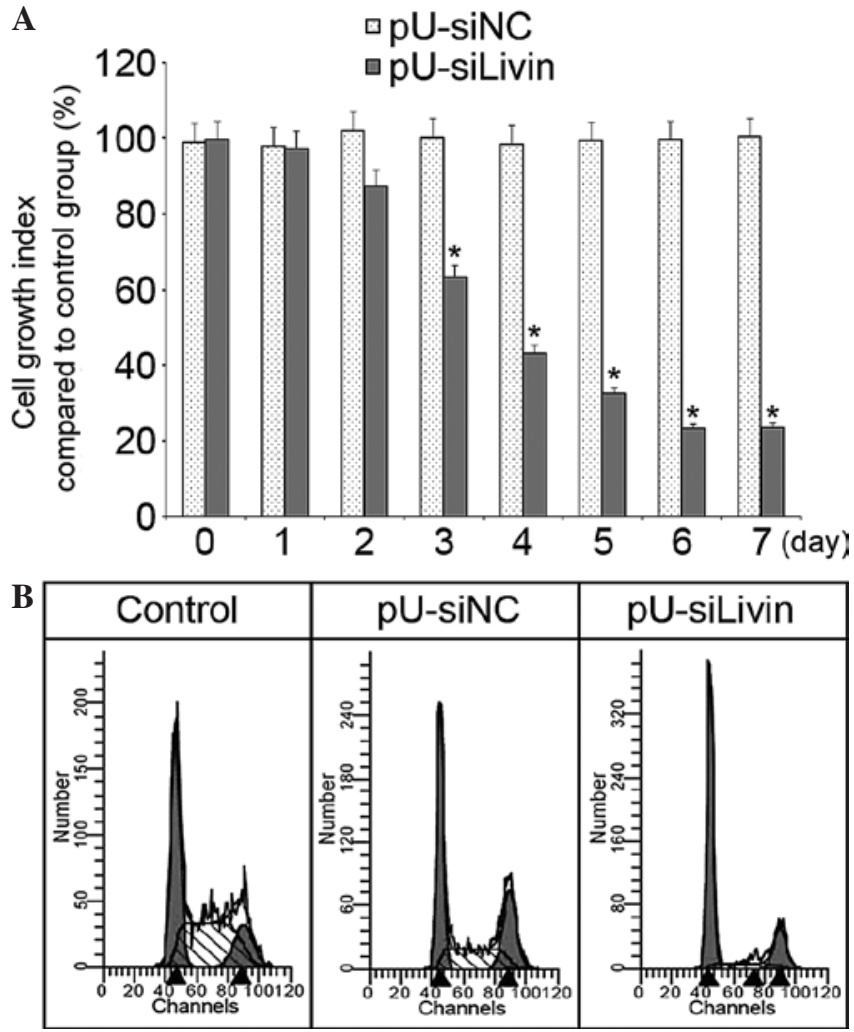

Figure 3. siRNA-mediated inhibition of livin blocks the growth of HCC cells. (A) Results of the MTT assay showing inhibition of SMMC-7721 cell growth by Livin siRNA. Each bar represents the mean \pm SD. ${ }^{*} \mathrm{P}<0.05$. (B) Flow cytometry analysis for the cell cycles of the cells. The experiments were repeated three times, with similar results.

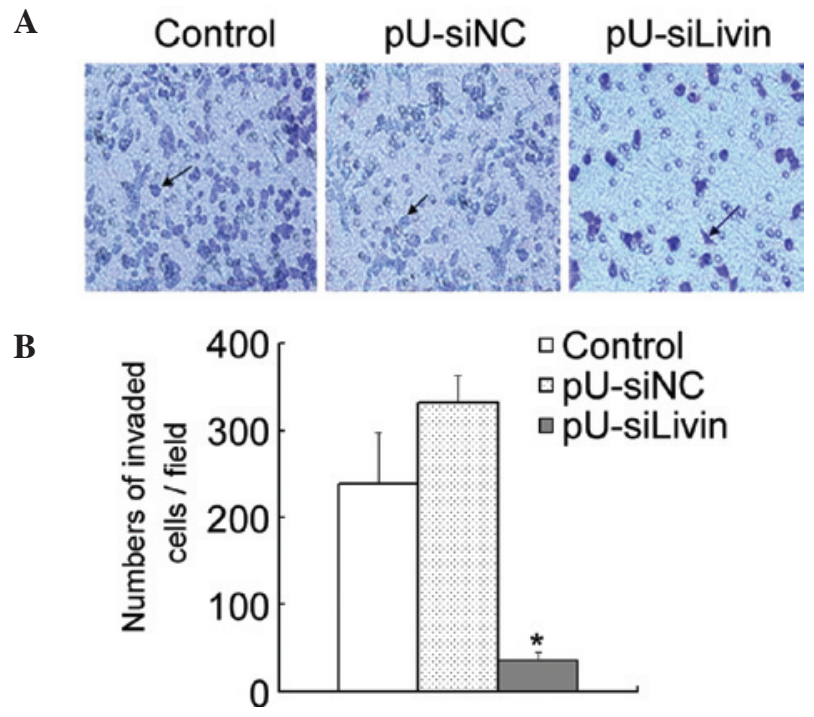

Figure 4. siRNA-mediated inhibition of livin blocks the invasion of HCC cells. Representative photomicrographs (A) and histogram (B) showing the invasive capability of cells in a chemoinvasion chamber. Each bar represents the mean $\pm \mathrm{SD}$. ${ }^{*} \mathrm{P}<0.05$. The experiments were repeated three times, with similar results.

and cancer cell resistance to radiotherapy and chemotherapy. The depletion of livin in cancer cells has been considered an ideal target for cancer therapy (9). Using siRNA targeting both livin isoforms, the tumor growth of human cancer cells 
in mice was inhibited (10). In addition, in vitro silencing of $\operatorname{livin} \beta$, but not livin $\alpha$, inhibits the proliferation of $\mathrm{HeLa}$ cells, and silencing livin sensitizes these cells to various proapoptotic stimuli including UV-irradiation, tumor-necrosis factor- $\alpha$ or etoposide treatment (11). The crucial role of livin in controlling apoptosis and its selective up-regulation in tumor tissues suggests that livin is a potential therapeutic target for anticancer strategies.

In the present study, we selected sequences of livin $\alpha$ and livin $\beta$ to design a siRNA-targeting livin gene, and successfully transfected it into the human HCC SMMC-7721 cell line. The transfectants showed significantly decreased levels of transcribed mRNA and protein, demonstrating that siRNA technology represents an extremely powerful tool to achieve specific and efficient livin gene inhibition in human HCC SMMC-7721 cells.

The inhibition of livin gene expression was associated with a strongly increased apoptotic response in the presence of the pro-apoptotic agent, indicating that interference with livin leads to a sensitization to pro-apoptotic stimuli. siRNAmediated silencing of livin expression led to an increase in the concentration of the active form of caspase-3, a main caspase for the induction of apoptotic cell death (12), and increased cleavage of the caspase substrate PARP. This result is consistent with previous data indicating that the livin protein acts as an inhibitor of caspase-3 $(13,14)$. However, caspase-7, -8 and -9 were not affected by the silencing of livin.

In addition, we observed that the down-regulation of livin expression induced HCC cell arrest in the G0/G1 phase of the cell cycle, which resulted in a significant inhibition of cell proliferation in vitro. These results are consistent with previous findings in human colorectal and lung cancer cells (10). It is well known that tumor invasion and metastasis are key prognostic factors. Regarding the effects of livin downregulation on the migration and invasion of HCC cells, the blockage of livin significantly inhibited the migration and invasion of HCC cells through a matrigel-coated Tranwell membrane.

In conclusion, the results of the present study indicate that livin expression not only provides HCC cells with increased resistance to apoptotic stimuli, but also contributes significantly to the proliferation and invasive capacity of HCC cells. Inhibition of livin may be a potential targeted approach for the treatment of HCC.

\section{Acknowledgements}

This study was supported by grants from the Shanghai Municipal Health Bureau (2008Y077), the Sub-Project of the National Grand Fundamental Research 863 Program of China (2007AA022004), and the Shanghai 'Phosphor' Project for specialists (09QA1407100).

\section{References}

1. Caldwell S and Park SH: The epidemiology of hepatocellular cancer: from the perspectives of public health problem to tumor biology. J Gastroenterol 44: 96-101, 2009.

2. Tung-Ping Poon R, Fan ST and Wong J: Risk factors, prevention, and management of postoperative recurrence after resection of hepatocellular carcinoma. Ann Surg 232: 10-24, 2000.

3. Deveraux QL and Reed JC: IAP family proteins - suppressors of apoptosis. Genes Dev 13: 239-252, 1999.

4. LaCasse EC, Mahoney DJ, Cheung HH, Plenchette S, Baird S and Korneluk RG: IAP-targeted therapies for cancer. Oncogene 27: 6252-6275, 2008.

5. Salvesen GS and Duckett CS: IAP proteins: blocking the road to death's door. Nat Rev Mol Cell Biol 3: 401-410, 2002.

6. Vucic D and Fairbrother WJ: The inhibitor of apoptosis proteins as therapeutic targets in cancer. Clin Cancer Res 13: 5995-6000, 2007.

7. Liu B, Han M, Wen JK and Wang L: Livin/ML-IAP as a new target for cancer treatment. Cancer Lett 250: 168-176, 2007.

8. Augello C, Caruso L, Maggioni M, et al: Inhibitors of apoptosis proteins (IAPs) expression and their prognostic significance in hepatocellular carcinoma. BMC Cancer 9: 125, 2009.

9. Nachmias B, Ashhab Y and Ben-Yehuda D: The inhibitor of apoptosis protein family (IAPs): an emerging therapeutic target in cancer. Semin Cancer Biol 14: 231-243, 2004.

10. Wang R, Lin F, Wang X, et al: Silencing Livin gene expression to inhibit proliferation and enhance chemosensitivity in tumor cells. Cancer Gene Ther 15: 402-412, 2008.

11. Crnkovic-Mertens I, Semzow J, Hoppe-Seyler F and Butz K: Isoform-specific silencing of the Livin gene by RNA interference defines Livin beta as key mediator of apoptosis inhibition in HeLa cells. J Mol Med 84: 232-240, 2006.

12. Mazumder S, Plesca D and Almasan A: Caspase-3 activation is a critical determinant of genotoxic stress-induced apoptosis. Methods Mol Biol 414: 13-21, 2008.

13. Kasof GM and Gomes BC: Livin, a novel inhibitor of apoptosis protein family member. J Biol Chem 276: 3238-3246, 2001.

14. Vucic D, Stennicke HR, Pisabarro MT, Salvesen GS and Dixit VM: ML-IAP, a novel inhibitor of apoptosis that is preferentially expressed in human melanomas. Curr Biol 10: 1359-1366, 2000. 